\title{
A Time-Dependent Numerical Model of Transmembrane Voltage Inducement and Electroporation of Irregularly Shaped Cells
}

\author{
Gorazd Pucihar, Damijan Miklavčič, and Tadej Kotnik*
}

\begin{abstract}
We describe a finite-element model of a realistic irregularly shaped biological cell in an external electric field that allows the calculation of time-dependent changes of the induced transmembrane voltage $(\Delta \Psi)$ and simulation of cell membrane electroporation. The model was first tested by comparing its results to the time-dependent analytical solution for $\Delta \Psi$ on a nonporated spherical cell, and a good agreement was obtained. To simulate electroporation, the model was extended by introducing a variable membrane conductivity. In the regions exposed to a sufficiently high $\Delta \Psi$, the membrane conductivity rapidly increased with time, leading to a modified spatial distribution of $\Delta \Psi$. We show that steady-state models are insufficient for accurate description of $\Delta \Psi$, as well as determination of electroporated regions of the membrane, and time-dependent models should be used instead. Our modeling approach also allows direct comparison of calculations and experiments. As an example, we show that calculated regions of electroporation correspond to the regions of molecular transport observed experimentally on the same cell from which the model was constructed. Both the time-dependent model of $\Delta \Psi$ and the model of electroporation can be exploited further to study the behavior of more complicated cell systems, including those with cell-to-cell interactions.
\end{abstract}

Index Terms-Electropermeabilization, finite elements, propidium iodide, transmembrane potential.

\section{INTRODUCTION}

$\mathbf{T}$ HE DISTRIBUTION of the voltage on the membranes of excitable or nonexcitable biological cells can be of interest in various theoretical and experimental settings, such as the activation of voltage-gated membrane channels, cardiac cell stimulation, or cell membrane electroporation [1]-[7]. In these settings, the cells are usually exposed to an external electric field, which induces a voltage across the cell membrane, termed the induced transmembrane voltage $(\Delta \Psi)$ [8], [9]. Unlike the native (resting) membrane voltage, which is constantly present on the cell membrane, $\Delta \Psi$ varies with the position on the cell membrane, and it is often important to accurately determine its spatial distribution. In electroporation, a detectable increase in membrane permeability and electric conductivity occurs in the

Manuscript received April 25, 2008; revised October 3, 2008 and December 22, 2008. First published February 6, 2009; current version published May 22, 2009. This work was supported by the Slovenian Research Agency (Project Z2-9229 and Program P2-0249). Asterisk indicates corresponding author.

G. Pucihar and D. Miklavčič are with the Faculty of Electrical Engineering, University of Ljubljana, Ljubljana SI-1000, Slovenia (e-mail: gorazd.pucihar@fe.uni-lj.si; damijan.miklavcic@fe.uni-lj.si).

$* \mathrm{~T}$. Kotnik is with the Faculty of Electrical Engineering, University of Ljubljana, Ljubljana SI-1000, Slovenia (e-mail: tadej.kotnik@fe.uni-lj.si).

Color versions of one or more of the figures in this paper are available online at http://ieeexplore.ieee.org.

Digital Object Identifier 10.1109/TBME.2009.2014244 membrane regions exposed to a sufficiently high transmembrane voltage [10], [11]. Although formation and stabilization of each single pore is a stochastic process, on the larger scale (cells, tissues) this effect only becomes detectable at $\Delta \Psi$ exceeding a certain value, $\Delta \Psi>\Delta \Psi_{C}$ (sometimes termed "threshold" or "critical" voltage) allowing to treat cell membrane electroporation as a deterministic process. Thus, for efficient electroporation and understanding of the phenomenon, accurate determination of the distribution of $\Delta \Psi$ on the cell membrane is important. Applications of electroporation include delivery of chemotherapeutic drugs to cancer cells (electrochemotherapy [12]-[15]), nonviral delivery of DNA to cells (gene electrotransfection [16]-[18]), transdermal drug delivery [19], [20], tissue ablation [21], [22], and sterilization [23].

In practice, $\Delta \Psi$ can be determined either experimentally, using sensitive potentiometric fluorescent dyes [10], [11], [24], [25], or theoretically, by analytical derivation [26], [27] or numerical modeling [28]-[34]. Analytically, $\Delta \Psi$ is derived by solving the Laplace equation in a suitable coordinate system and with appropriate boundary conditions [8], [9], [26], [27]. The simplest such solution is the steady-state solution for a spherical cell, which reads

$$
\Delta \Psi=\frac{3}{2} E R \cos \theta
$$

where $E$ is the external electric field, $R$ is the cell radius, and $\theta$ is the angle between the direction of the field and the normal from the center of the cell to the point of interest on the cell surface. Introducing the time variable and accounting for the electric conductivities and dielectric permittivities of the domains, one obtains time-dependent solutions; the first-order solution [35]

$$
\Delta \Psi(t)=f_{S} E R\left(1-\mathrm{e}^{(-t / \tau)}\right) \cos \theta
$$

where detailed derivation of the function $f_{S}$ and the time constant $\tau$ are given in [27] and [35], and the second-order solution [27]

$$
\begin{aligned}
\Delta \Psi(t)=[ & a+f_{\mathrm{S} 1} \operatorname{ER}\left(1-\mathrm{e}^{\left(-t / \tau_{1}\right)}\right) \\
& \left.+f_{\mathrm{S} 2} E R\left(1-\mathrm{e}^{\left(-t / \tau_{2}\right)}\right)\right] \cos \theta
\end{aligned}
$$

where $a, f_{\mathrm{S} 1}, f_{\mathrm{S} 2}, \tau_{1}$, and $\tau_{2}$ are given in [27] and [36]. Solving the Laplace equation in a different coordinate system also yields solutions for several other regular cells shapes, such as cylinders, spheroids, and ellipsoids [37]-[39].

Realistic cells, however, can deviate considerably from such regular shapes, and for such geometries an explicit analytical solution (either steady-state or time-dependent) does not exist. 
Besides, cells are typically also not isolated (far apart from other objects), but grow in clusters (in tissues) or in monolayers (attached to the bottom of a dish). Employing analytical solutions for spherical and spheroidal cells to these realistic cells can yield inaccurate results, and thus in realistic settings, the experimental and numerical methods are often the only feasible approaches for determination of $\Delta \Psi$. Among numerical methods, the established approaches are modeling with resistive-capacitive transport lattices [40]-[42], finite differences [30], [33], [43], and with finite elements [28], [29], [31], [34], but other methods, such as hybrid finite-element modeling are also applicable [44].

With steady-state $\Delta \Psi$, electroporation can be modeled deterministically as occurring in the area of the membrane where $\Delta \Psi$ exceeds a certain value $\Delta \Psi_{C}$. This approach is simple to implement, but the error in estimating the extent of membrane electroporation can be considerable. In this paper, we show that time-dependent models, which account for the fact that both $\Delta \Psi$ and the conductivity of the electroporated membrane vary with time, yield much more realistic results. Most often, such models are solved numerically using the finite-difference method. The advantage of this approach is that the expressions describing $\Delta \Psi$ and electroporation are easy to implement, but these models are generally based on either simplified geometry [30], [33], [45], or concentrated parameters such as $R C$-lattices [40]-[42]. Some attempts were made to model arbitrarily shaped cells or clusters of such cells in the steady state as well as in the time and frequency domains, but these were all confined to a 2-D space [32], [40], [46], [47]. The finite-element method that we employ here is more suitable for modeling cells as complex, more realistic 3-D shapes.

We recently developed and described a method for constructing realistic finite-element models of cells of irregular shapes from their cross-sectional images [34]. This method is efficient in calculating the steady-state $\Delta \Psi$, but is not suitable for simulating electroporation, which is a dynamic process, with membrane conductivity in electroporated regions dependent on $\Delta \Psi$ and varying with time. Here, we present further improvement of this method, which allows for the calculation of the timedependent changes of $\Delta \Psi$ and simulation of electroporation. This is, to our knowledge, the first report on time-dependent modeling of electroporation in realistically shaped cells using the finite-element method. Another advantage of the method presented here is the possibility to directly validate the numerical results by comparing them to the experimental measurements.

\section{Materials AND MethodS}

\section{A. Construction of a Realistic 3-D Numerical Model of a Cell}

3-D model of an irregularly shaped cell was constructed from a sequence of microscopic fluorescence images representing cross sections of a Chinese hamster ovary $(\mathrm{CHO})$ cell attached to the cover glass. A more detailed description of the model construction can be found in [34]. Briefly, fluorescence images were obtained by staining the cell with a fluorescent dye di8 -anepps. The images, acquired with a charge-coupled device (CCD) camera (VisiCam 1280, Visitron, Germany), mounted on a fluorescence microscope (AxioVert 200, Zeiss, Germany),

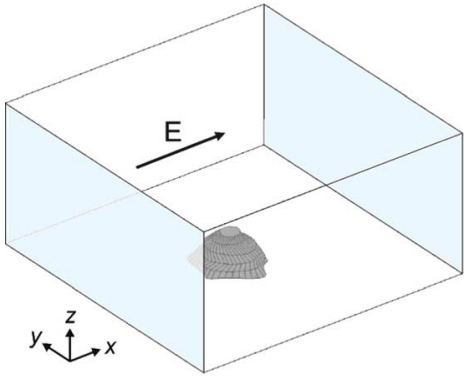

Fig. 1. 3-D model of a CHO cell attached to the cover glass. The cell was constructed from six parallel horizontal cross sections and placed at the bottom of a box measuring $79 \mu \mathrm{m} \times 79 \mu \mathrm{m} \times 38 \mu \mathrm{m}$. The gray-shaded faces were the electrodes, one set to $7.9 \mathrm{~V}$ and the other to the ground (electric field $1000 \mathrm{~V} / \mathrm{cm}$ ).

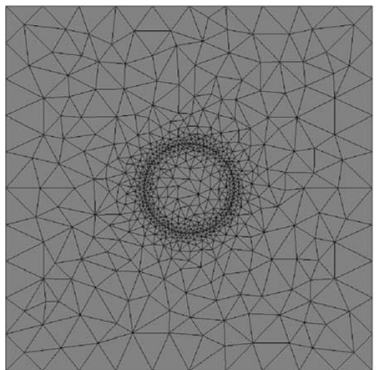

(a)

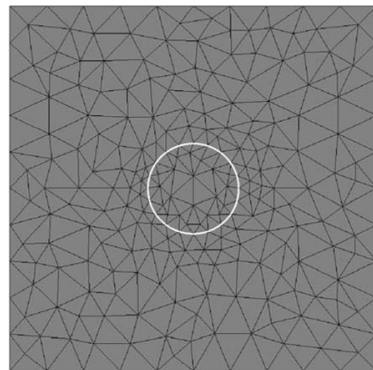

(b)
Fig. 2. Mesh of a model of a spherical cell with radius $10 \mu \mathrm{m}$. A cross section through the center of the cell is shown. (a) Membrane with thickness of $0.3 \mu \mathrm{m}$ was incorporated in the model, which is still about 70 times thicker than the real membrane. Number of mesh elements was 57809 (79 684 DOF). (b) Membrane was modeled as a boundary condition. Number of mesh elements was 10000 (15 386 DOF).

were processed to obtain contours of the cell. The contours were transformed to solid planes, combined into a 3-D object, and imported to the COMSOL workspace (COMSOL 3.4 Inc., Burlington, MA) (Fig. 1).

Instead of a direct incorporation of a cell membrane in the model, the membrane was replaced by a surface to which a boundary condition was assigned [34]

$$
J(t)=\frac{\lambda_{m 0}\left(\Psi_{i}-\Psi_{o}\right)}{h}+\frac{\varepsilon_{0} \varepsilon_{m}}{h} \frac{\partial\left(\Psi_{i}-\Psi_{o}\right)}{\partial t} .
$$

Here, $J$ is the current density, $\lambda_{m 0}$ is the conductivity of the nonporated membrane, $h$ is the membrane thickness, $\varepsilon_{m}$ is the relative permittivity of the membrane, and $\Psi_{o}$ and $\Psi_{i}$ are the electric potentials at the outer and inner surface of the membrane, respectively. The first and the second term in (4) represent the conductive and the capacitive component of the electric current through the membrane. The substitution of the membrane by a boundary condition does not affect the electric potential distribution outside the membrane, and is thus valid as long as the events inside the membrane are not of interest. In a model constructed in this way, the mesh of finite elements is generated without difficulty, as very small elements corresponding to the membrane interior are avoided [34]. To illustrate this, Fig. 2 shows a mesh generated on a model of a spherical cell with the membrane incorporated, and with the membrane replaced by a boundary condition given by (4). 


\section{B. Model Settings and Calculations of the Induced Voltage}

The calculations were performed in COMSOL using the Electric Currents, Transient Analysis application mode, with more details given in [34]. The conductivity of the cell interior was set to $0.3 \mathrm{~S} / \mathrm{m}$ and that of the cell exterior to $0.14 \mathrm{~S} / \mathrm{m}$ [27], [48]. The opposite vertical faces of the block were modeled as electrodes, which was done by assigning a fixed electric potential to each of these faces. One electrode was set to $7.9 \mathrm{~V}$ and the other to the ground to obtain the electric field of $1000 \mathrm{~V} / \mathrm{cm}$, which was also the applied electric field in the experiments (see Section II-D). The remaining faces of the block were modeled as insulating. The mesh of finite elements (tetrahedral Lagrange quadratic finite elements) was generated using adaptive meshing and consisted of approximately 50000 finite elements and 88000 DOF. The electric potential $\Psi$ inside and outside the cell was then computed by solving the equation

$$
-\nabla(\lambda \nabla \Psi)-\varepsilon_{0} \varepsilon_{r} \nabla\left(\frac{\partial}{\partial t}(\nabla \Psi)\right)=0 .
$$

Here, $\varepsilon_{0}$ is dielectric permittivity of the vacuum, $\varepsilon_{r}$ is relative dielectric permittivity, and $\lambda$ is conductivity. The equation was solved in COMSOL, using the direct Pardiso solver. Finally, the induced transmembrane voltage $(\Delta \Psi)$ was calculated as the difference between electric potentials on both sides of the membrane

$$
\Delta \Psi=\Psi_{i}(t)-\Psi_{o}(t)
$$

and was plotted as a function of the arc length.

\section{Model of Electroporation}

Electroporation is described theoretically as formation of transient hydrophilic pores in the lipid bilayer of the plasma membrane, which occurs during the exposure of a cell to an external electric field [49]-[51]. The density of pores increases with the amplitude of the field, which eventually results in a detectable increase in membrane conductivity and membrane permeability [10], [52]-[56]. Since the pores provide new conducting pathways for the transmembrane current density $J$, electroporation can be modeled by introducing an additional term $J_{\mathrm{EP}}$ to (4)

$$
J(t)=\frac{\lambda_{m 0}\left(\Psi_{i}-\Psi_{o}\right)}{h}+\frac{\varepsilon_{0} \varepsilon_{m}}{h} \frac{\partial\left(\Psi_{i}-\Psi_{o}\right)}{\partial t}+J_{\mathrm{EP}}(t) .
$$

De Bruin and Krassowska [30] derived the expression for $J_{\mathrm{EP}}$, which, in its simplest form, can be written as

$$
J_{\mathrm{EP}}(t)=i_{\mathrm{EP}}(t) N(t)
$$

where $i_{\mathrm{EP}}$ is the current through a single pore

$$
i_{\mathrm{EP}}(t)=\left(\Psi_{i}-\Psi_{o}\right) \lambda_{\mathrm{P}} \pi r_{\mathrm{P}}^{2} \frac{A}{h}
$$

\begin{tabular}{|c|c|c|}
\hline Symbol & Quantity & Value \\
\hline$R$ & cell radius & $1 \times 10^{-5} \mathrm{~m}$ \\
\hline$\alpha$ & creation rate coefficient & $1 \times 10^{9} \mathrm{~m}^{-2} \mathrm{~s}^{-1}[30]$ \\
\hline$N_{0}$ & equilibrium pore density & $1.5 \times 10^{9} \mathrm{~m}^{-2}[30]$ \\
\hline$V_{\mathrm{EP}}$ & characteristic voltage of electroporation & $170 \mathrm{mV}$ \\
\hline$q$ & pore creation rate & $2.46[30]$ \\
\hline$r_{\mathrm{P}}$ & pore radius & $0.8 \times 10^{-9} \mathrm{~m}$ \\
\hline$h$ & membrane thickness & $5 \times 10^{-9} \mathrm{~m}[27]$ \\
\hline$\varepsilon_{0}$ & dielectric permittivity of the vacuum & $8.85 \times 10^{-12} \mathrm{As} / \mathrm{Vm}$ \\
\hline$\varepsilon_{\mathrm{m}}$ & relative permittivity of the membrane & $5[27]$ \\
\hline$\varepsilon_{0}$ & relative permittivity of the medium & $80[27]$ \\
\hline$\varepsilon_{\mathrm{i}}$ & relative permittivity of the cytoplasm & $80[27]$ \\
\hline$\lambda_{\mathrm{o}}$ & medium conductivity & $0.14 \mathrm{~S} / \mathrm{m}[48]$ \\
\hline$\lambda_{\mathrm{i}}$ & cytoplasmic conductivity & $0.3 \mathrm{~S} / \mathrm{m}[27]$ \\
\hline$\lambda_{\mathrm{m} 0}$ & membrane conductivity (nonporated) & $5 \times 10^{-7} \mathrm{~S} / \mathrm{m}[27]$ \\
\hline$\lambda_{\mathrm{P}}$ & conductivity of solution inside the pore & $0.16 \mathrm{~S} / \mathrm{m}$ \\
\hline$N$ & relative entrance length of pores & $0.15[30]$ \\
\hline$w_{0}$ & energy barrier within pore & $2.65[30]$ \\
\hline$F$ & Faraday's constant & $9.65 \times 10^{4} \mathrm{Cmol}^{-1}$ \\
\hline$R$ & gas constant & $8314 \mathrm{~J} \mathrm{~K}^{-1} \mathrm{~mol}^{-1}$ \\
\hline$T$ & absolute temperature & $295 \mathrm{~K}$ \\
\hline
\end{tabular}

with $A$ given by (8b), as shown at the bottom of this page, where $v_{m}=\left(\Psi_{i}-\Psi_{o}\right)(F / R T), F, R$, and $T$ the Faraday's constant,
TABLE I

PARAMETERS OF THE ELECTROPORATION MODEL

the gas constant, and absolute temperature, respectively, and $N$ the pore density characterized by the following differential equation [30], [57]:

$$
\frac{d N(t)}{d t}=\alpha e^{\left(\Delta \Psi(t) / V_{\mathrm{EP}}\right)^{2}}\left(1-\frac{N(t)}{N_{0}} e^{-q\left(\Delta \Psi(t) / V_{\mathrm{EP}}\right)^{2}}\right) .
$$

Inserting (7) and (8) into (6), we obtain

$$
J(t)=\frac{\left(\Psi_{i}-\Psi_{o}\right)}{h} \lambda_{m}(t)+\frac{\varepsilon_{0} \varepsilon_{m}}{h} \frac{\partial\left(\Psi_{i}-\Psi_{o}\right)}{\partial t}
$$

where $\lambda_{m}(t)=\lambda_{m 0}+N(t) \lambda_{P} \pi r_{P}^{2} A$ is the variable conductivity of the electroporated membrane. The definitions and typical values of the constants in (8) and (9) are given in Table I. The parameter $V_{\mathrm{EP}}$ determines (but is not equal to) $\Delta \Psi_{C}$ at which electroporation becomes significant, with the explicit relation between $V_{\mathrm{EP}}$ and $\Delta \Psi_{C}$ given in [30]. In a separate study, we found that $\Delta \Psi_{C}$ can vary considerably between attached cells of the same type, ranging approximately from 500 to $1000 \mathrm{mV}$ [58]. In the study presented here, the mean of this range was used, $\Delta \Psi_{C}=750 \mathrm{mV}$ (equivalent to $V_{\mathrm{EP}}=170 \mathrm{mV}$ ). The value of $\alpha$ was set to $10^{9} \mathrm{~m}^{-2} \cdot \mathrm{s}^{-1}$, but varying this parameter within its physically realistic range (from $0.92 \times 10^{9}$ to $2 \times 10^{9} \mathrm{~m}^{-2} \cdot \mathrm{s}^{-1}$ [30]) does not affect the results significantly.

This model disregards the resting membrane voltage, because it is small compared to $\Delta \Psi_{C}$. This is particularly true for the $\mathrm{CHO}$ cells, for which the resting voltage is about $-10 \mathrm{mV}$ [59], i.e., at least 20 times lower than any transmembrane voltage reported to lead to detectable electroporation [58], [60], [61]. The model also assumes that both the pore radius and the conductivity inside the pore are constant. Nevertheless, $\lambda_{m}$ in this

$$
A=\frac{e^{v_{m}}-1}{e^{v_{m}}\left(w_{0} e^{w_{0}-n v_{m}}-n v_{m}\right) /\left(w_{0}-n v_{m}\right)-\left(w_{0} e^{w_{0}+n v_{m}}+n v_{m}\right) /\left(w_{0}+n v_{m}\right)}
$$


(a)

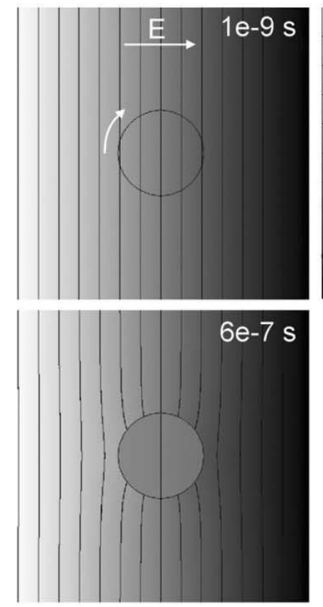

(b)

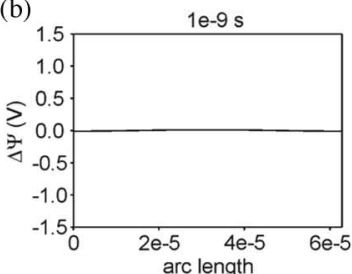

$6 e-7 \mathrm{~s}$

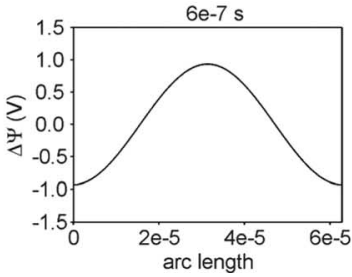

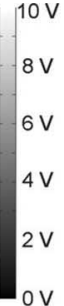

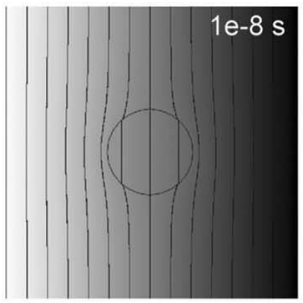

$1 e-6 s$

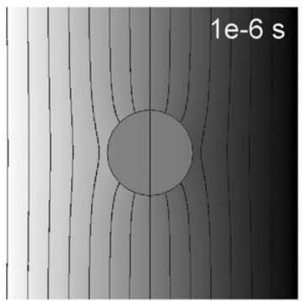

$1 \mathrm{e}-8 \mathrm{~s}$
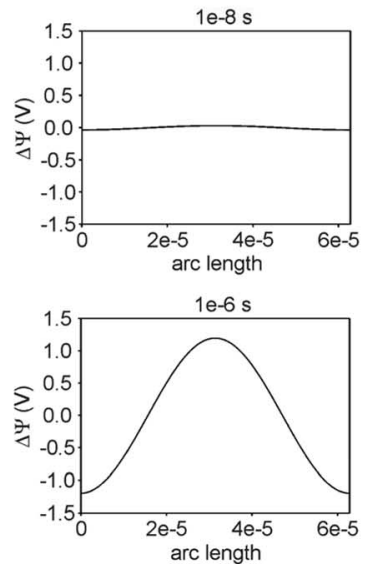
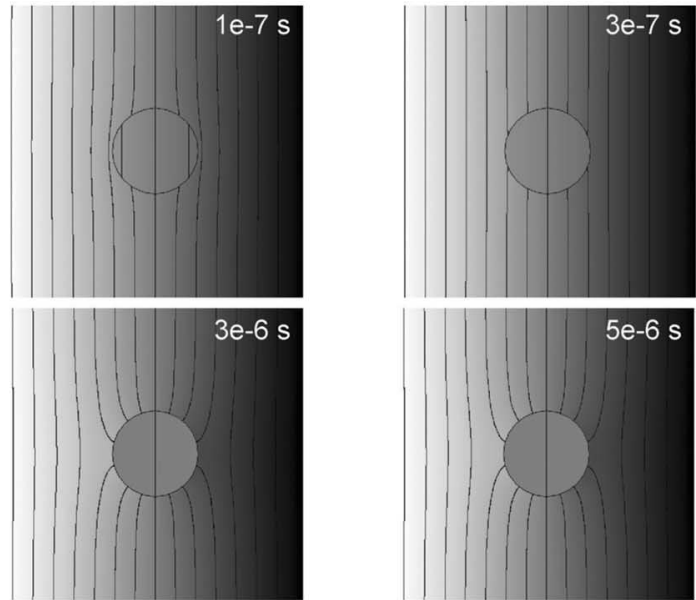

$5 e-6 s$

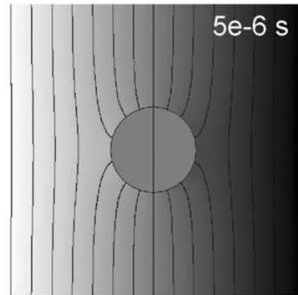

$1 \mathrm{e}-7 \mathrm{~s}$
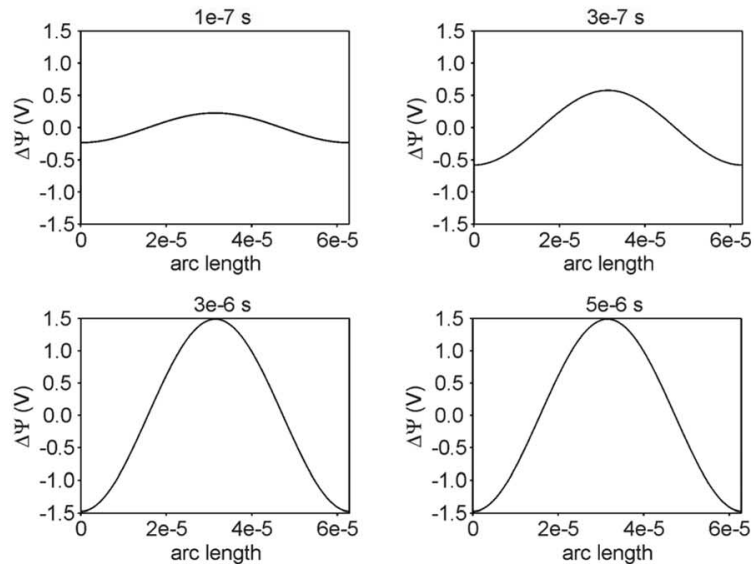

Fig. 3. Induced transmembrane voltage $\Delta \Psi$ calculated on a model of a spherical cell. (a) Calculated distribution of the electric potential around and inside a cell in the $x-y$ plane crossing the center of the cell. The black curves are the equipotentials, and the arrow marks the path along which the potential was measured. (b) Corresponding time courses of $\Delta \Psi$. The calculations were performed for a model of a spherical cell with $R=10 \mu \mathrm{m}, d=5 \mathrm{~nm}, \lambda_{o}=0.14 \mathrm{~S} / \mathrm{m}$, $\lambda_{i}=0.3 \mathrm{~S} / \mathrm{m}, \lambda_{m}=5 \times 10^{-7} \mathrm{~S} / \mathrm{m}, \varepsilon_{m}=5, \varepsilon_{o}=\varepsilon_{i}=80, E=1000 \mathrm{~V} / \mathrm{cm}$, with the cell positioned in the center of a box with dimensions of $100 \mu \mathrm{m} \times$ $100 \mu \mathrm{m} \times 100 \mu \mathrm{m}$.

model does vary with time, as it is a function of $\Delta \Psi$ and $N$, which are both time dependent [see (5b) and (9)]. The exponential dependence in (9) also implies that the increase of $N$ results in a rapid increase of $\lambda_{m}$, thereby lowering $\Delta \Psi$ in the porated area in a self-regulating manner (see Fig. 6). More details on the derivation of (8) and (9) can be found in [30] and [57].

Equation (9) was solved on the membrane of the cell, using the Weak form, boundary PDE application mode in COMSOL, simultaneously with the calculation of the electric potential [see (5a)]. The time required to obtain a solution was less than $6 \mathrm{~min}$ on a PC with a $2.67 \mathrm{GHz}$ Intel Core 2 Duo CPU and 2 GB RAM.

\section{Monitoring the Course of Electroporation}

$\mathrm{CHO}$ cells were grown on cover glasses in a culture medium (F-12, Sigma, Saint Louis, MO). When cells attached to the glass (app. $12 \mathrm{~h}$ after plating) the culture medium was replaced by a pulsation buffer [48], which contained $100 \mu \mathrm{m}$ of membraneimpermeable fluorescent dye propidium iodide (PI, Sigma). Cells were then exposed to a $400 \mathrm{~V}, 200 \mu$ s electroporating pulse delivered to two parallel needle electrodes with a $4 \mathrm{~mm}$ distance between them (electric field was thus approximately $1000 \mathrm{~V} / \mathrm{cm}$ ). The fluorescence of the dye increased consider- ably after entering the electroporated cell, which was monitored with the imaging system, described in Section II-A.

\section{RESULTS AND DISCUSSION}

\section{A. Calculations of the Induced Transmembrane Voltage}

1) Comparison to the Analytical Solution for a Spherical Cell: The model was first validated by comparing the calculated and analytically derived induced transmembrane voltage $(\Delta \Psi)$ for a spherical cell. Fig. 3(a) shows the spatial distribution of the electric potential in the model of a spherical cell with a radius of $10 \mu \mathrm{m}$ at different times after the onset of the external electric field $(1000 \mathrm{~V} / \mathrm{cm})$, while the time course of $\Delta \Psi$, sampled clockwise around the perimeter of the cell, is presented in Fig. 3(b). The calculations show that after a step change of the electric field, $\Delta \Psi$ gradually forms on the cell membrane, with a time constant of voltage inducement of approximately $0.6 \mu \mathrm{s}$. After a few microseconds, a steady-state value of $\Delta \Psi$ is obtained. The amplitude of $\Delta \Psi$ depends on the position on the cell membrane- the regions of the cell facing the positive and ground electrode experience the highest absolute values of $\Delta \Psi$, -1.5 and $1.5 \mathrm{~V}$, respectively. 


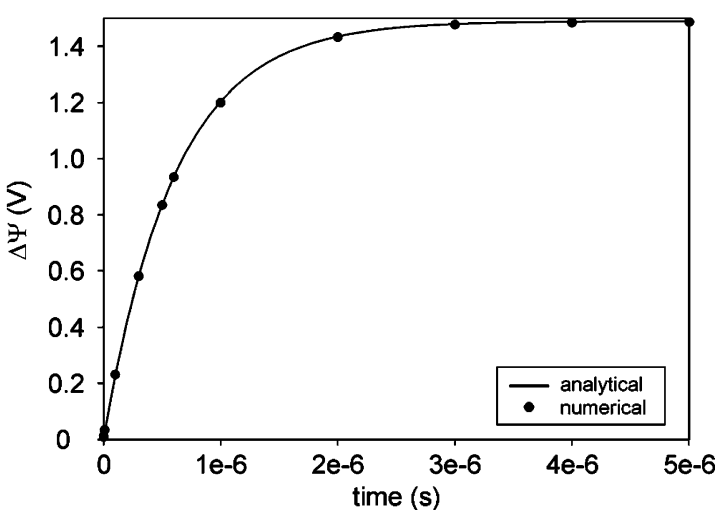

(a)

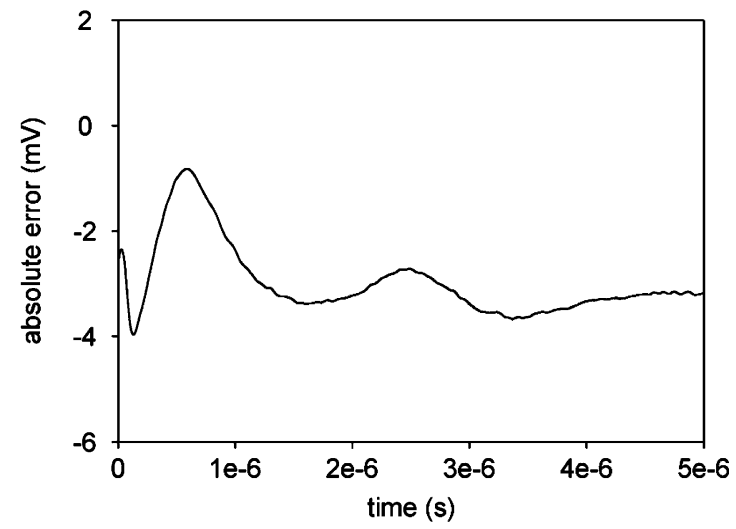

(b)

Fig. 4. Comparison of the calculated and analytically derived $\Delta \Psi$. (a) Time course of calculated (symbols) and analytically derived (curve) $\Delta \Psi$ [see (3) $, \cos \theta=0, a=8 \times 10^{-3}, f_{\mathrm{S} 1}=1.48, f_{\mathrm{S} 2}=1.2 \times 10^{-3}, \tau_{1}=6.07 \times$ $\left.10^{-7} \mathrm{~s}, \tau_{2}=3,67 \times 10^{-9} \mathrm{~s}\right]$. (b) Absolute error with respect to the analytical solution. The model settings are given in caption of Fig. 3.

Finally, Fig. 4 shows the comparison of the calculated and analytically derived $\Delta \Psi$ [see (3), at $\cos \theta=0$ ] demonstrating a good agreement between both solutions. The absolute error with respect to the analytical solution remains within the range of -4 and $-1 \mathrm{mV}$ throughout the calculated time interval [Fig. 4(b)]. This shows that the model is sufficiently accurate for all practical applications of electroporation, where $\Delta \Psi$ is in the range of hundreds of millivolts. For accurate modeling of exposures to pulses with durations or rise times in the nanoseconds range, the dielectric relaxation effects would have to be accounted for, which would amount to replacing the constant dielectric permittivities by suitable functions of frequency (or time derivative) of the electric field.

2) Transmembrane Voltage Induced on an Irregularly Shaped Cell: For irregularly shaped cells, analytical solutions cannot be derived, and numerical methods present one of the remaining possibilities for determination of $\Delta \Psi$. In our approach, the realistic model of an irregularly shaped cell was constructed from six parallel cross sections of a $\mathrm{CHO}$ cell. The distribution of the electric potential around and inside the cell is shown in Fig. 5(a) and the induced transmembrane voltage $(\Delta \Psi)$ in Fig. 5(b). Compared to the results for a spherical cell, the steady-state value of $\Delta \Psi$ is lower here, mostly due to the fact that the cell in Fig. 5, grown on a cover glass, was quite flat and thus represented "less of an obstacle" to the external field. As a consequence of the irregular shape of the cell the spatial distribution of $\Delta \Psi$ deviated from the cosine shape. For cells with more complex shape, such as fibroblasts or neuronal cells, the deviation of $\Delta \Psi$ from a cosine shape would be significantly more pronounced.

In a more simplified approach, an irregular cell such as the one shown in Figs. 1 and 5 would be modeled as a geometrical body of a regular shape, such as a hemisphere or a spherical cap. However, when a detailed knowledge of $\Delta \Psi$ is important as, e.g., in electroporation (see next section), this would lead to considerable inaccuracies, and a more realistic modeling of the cell shape improves the accuracy substantially.

\section{B. Modeling of Electroporation}

Calculations presented in Figs. 3 and 5 show that the maximal $\Delta \Psi$ in both cells exceeded $1 \mathrm{~V}$, implying that they should both be electroporated. With steady-state models, the size of the electroporated surface of the cell membrane would be characterized as the region, where $\Delta \Psi>\Delta \Psi_{C}$ (as explained in Section II-C, we set $\Delta \Psi_{C}$ at $750 \mathrm{mV}$ ). However, as will be demonstrated later, this approach only gives a rough estimate of the real size of the electroporated surface. A more realistic approach is to consider electroporation as a dynamic process, with membrane conductivity depending on $\Delta \Psi$ and varying with time [see (10)].

The model of electroporation was first tested on a spherical cell. After a delay of approximately $600 \mathrm{~ns}$, membrane conductivity $\lambda_{m}$ in the regions of the cell facing the electrodes rapidly increased, reflecting electroporation of this part of the membrane [Fig. 6(a)]. The area of the electroporated regions continued to increase until the steady-state value was reached approximately $5 \mu$ s after the start of the pulse. Electroporation was symmetrical on both sides of the cell, and was localized to the regions of the membrane exposed to values of $\Delta \Psi$ exceeding $\Delta \Psi_{C}$. The spatial distribution of $\Delta \Psi$ in the electroporated regions was distorted with respect to the shape calculated on the nonporated membrane (cf. Figs. 3(b) and 6(b) - solid curve), which can be explained with the increased membrane conductivity in these regions. The temporal and spatial distribution of $\Delta \Psi$ calculated on a spherical cell during electroporation (Fig. 6(b)—solid curves) were qualitatively similar to $\Delta \Psi$ previously measured by Hibino and coworkers on sea urchin eggs using a potentiometric fluorescent dye and a fast imaging system [10], [11]. If the electrical and geometrical parameters of the cell model are set equal to those specified in their study, the time course of membrane conductivity for the first $5 \mu \mathrm{s}$ is comparable to their measurements (e.g., $2.3 \mathrm{~S} / \mathrm{cm}^{2}$ compared to $4.8 \mathrm{~S} / \mathrm{cm}^{2}$ at $5 \mu \mathrm{s})$. However, at later times the simulation predicted a steady membrane conductivity, while the measurements by Hibino and coworkers show a continuing slow increase, suggesting that also at later times, pores can either increase or coalescence into larger pores.

Next, electroporation was modeled on an irregularly shaped cell. Results presented in Fig. 6(c) and (d) show that the time 
(a)

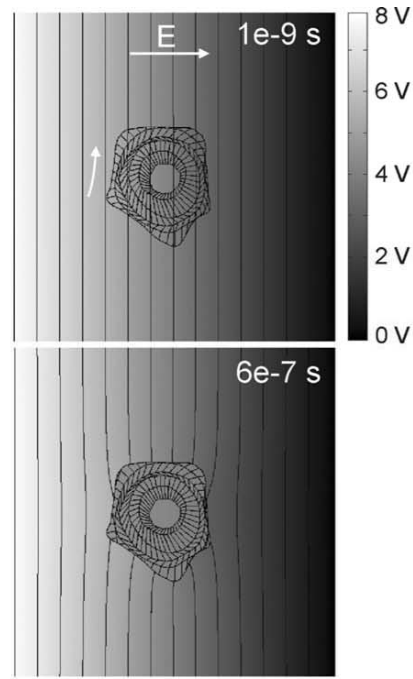

(b)
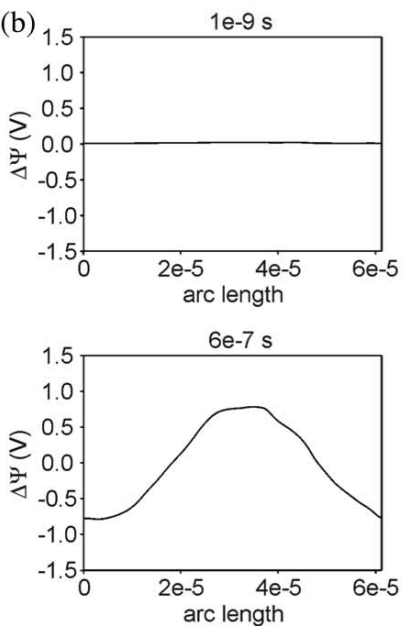
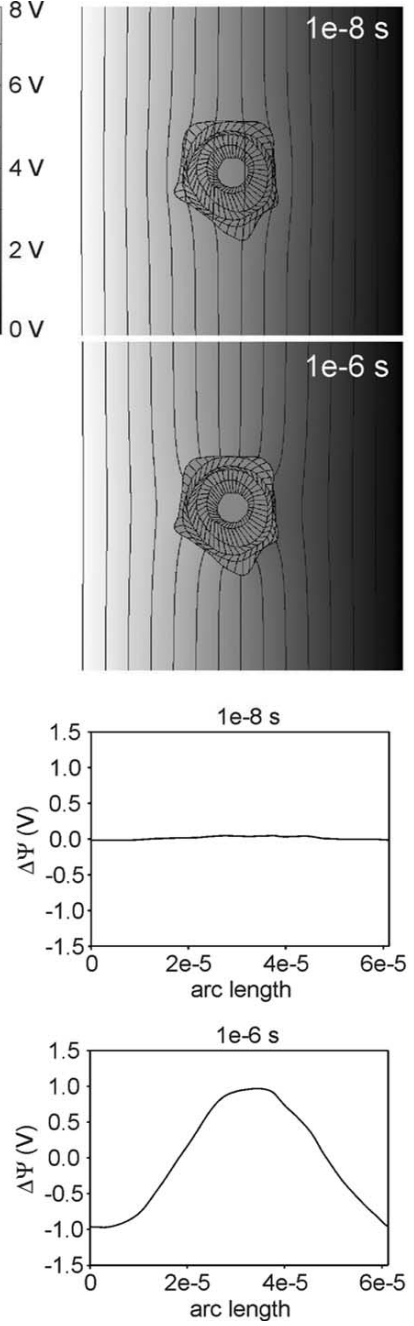
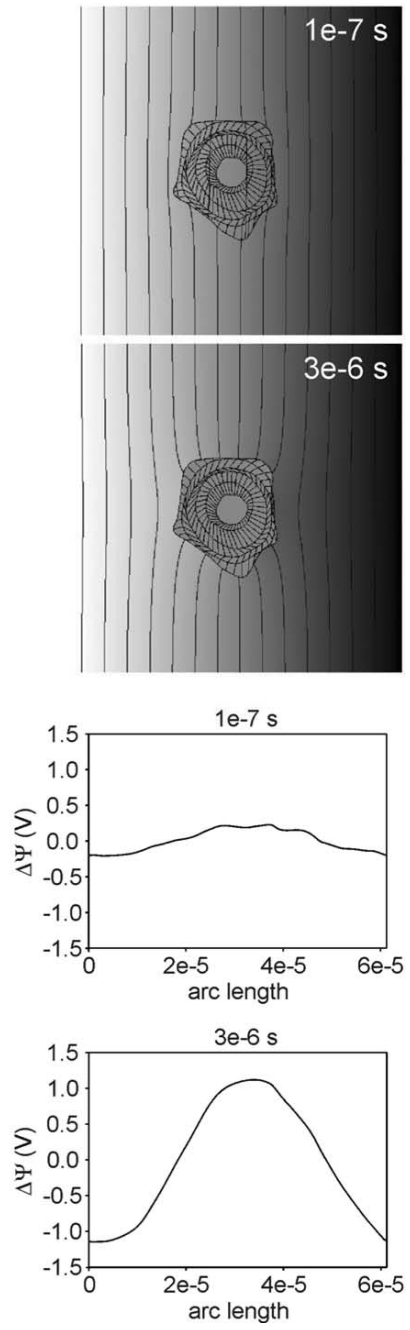
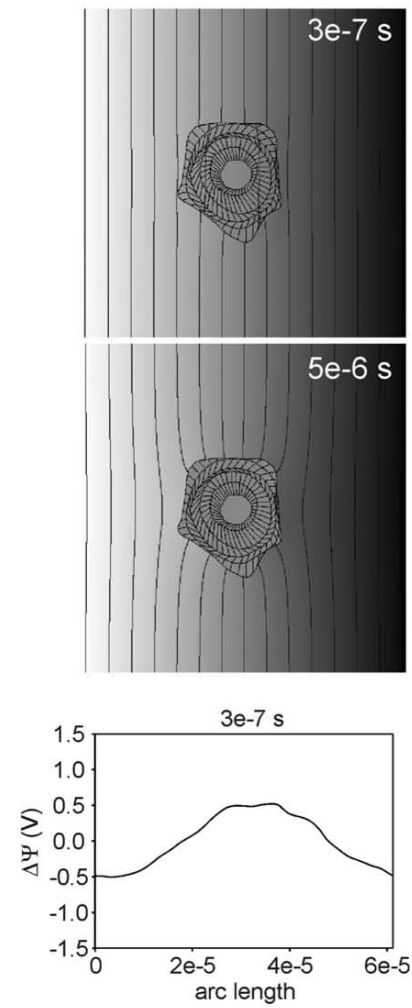

$3 e-7 s$

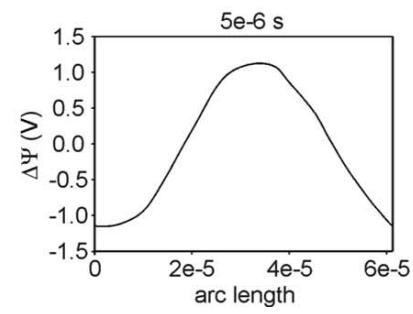

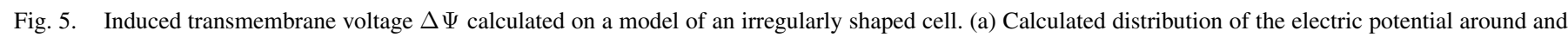

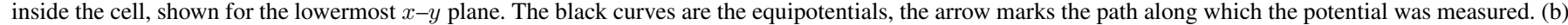

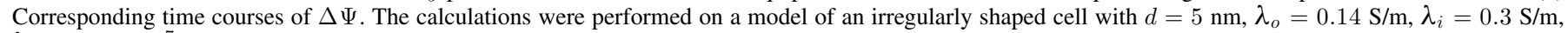
$\lambda_{m}=5 \times 10^{-7} \mathrm{~S} / \mathrm{m}, \varepsilon_{m}=5, \varepsilon_{o}=\varepsilon_{i}=80$, and $E=1000 \mathrm{~V} / \mathrm{cm}$.

course and spatial distribution of $\Delta \Psi$ and membrane conductivity are different from those observed for a spherical cell, which is due to different size and shape of both cells. Small ripples in the spatial distribution of $\Delta \Psi$ are characteristic for irregularly shaped cells and are reflected in an inhomogeneous electroporation of this cell. More specifically, compared to a spherical cell, the irregularly shaped cell was electroporated asymmetricallythe side of the cell facing the positive electrode was porated more intensely and the size of the whole electroporated region was slightly larger on this side of the cell [Fig. 6(d)]. We should emphasize that asymmetric electroporation of this cell was entirely due to its irregular shape. Experimentally, some asymmetry could also be due to the resting membrane voltage, but as we explain in Section II-C, this contribution is rather small and was neglected in our model. Electroporation was most pronounced in the protrusions of the cell facing the electrodes [marked with arrows in Fig. 6(c)], which is in agreement with previously reported experimental observations on attached cells [62].
Another interesting feature is the spatial distribution of $\Delta \Psi$ calculated in the nonporated regions of electroporated cells, i.e., in the regions, where $\Delta \Psi<\Delta \Psi_{C}$. Namely, $\Delta \Psi$ in the nonporated regions of a porated cell is lower than $\Delta \Psi$ calculated in the same regions of a nonporated cell of the same shape (cf. dotted line-nonporated cell, and solid line-porated cell in Fig. 7). This is due to the fact that part of the current that was flowing around the cell before electroporation, now flows through the electroporated regions of the membrane and thereby affects the distribution of $\Delta \Psi$ on the whole cell, including the nonporated regions. This also demonstrates why steady-state models might be inaccurate in describing the extent of electroporation. Namely, in these models, electroporated regions could be determined only from the steady-state distribution of $\Delta \Psi$. The results shown in Figs. 7 and 8 imply that such an approach can considerably overestimate the electroporated surface of the cell (cf. dashed line-time-dependent model, and dotted line-steady-state model, in Fig. 8). In other words, if $\Delta \Psi_{C}$ is determined based on combining experimental observations 


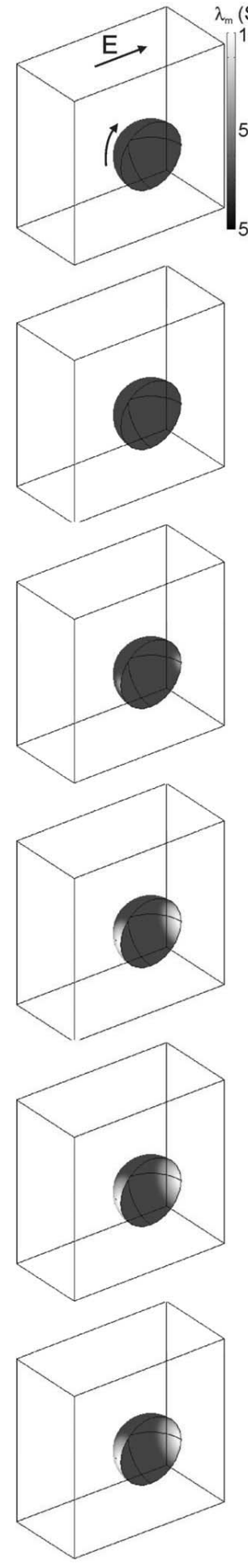

(a)
$1 \mathrm{e}-8 \mathrm{~s}$
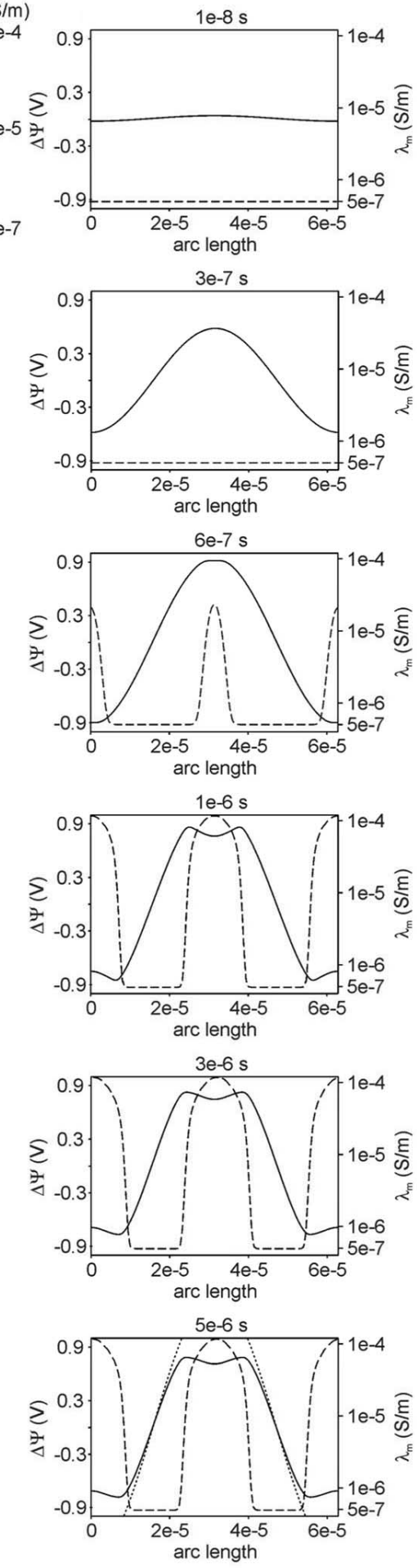

(b)
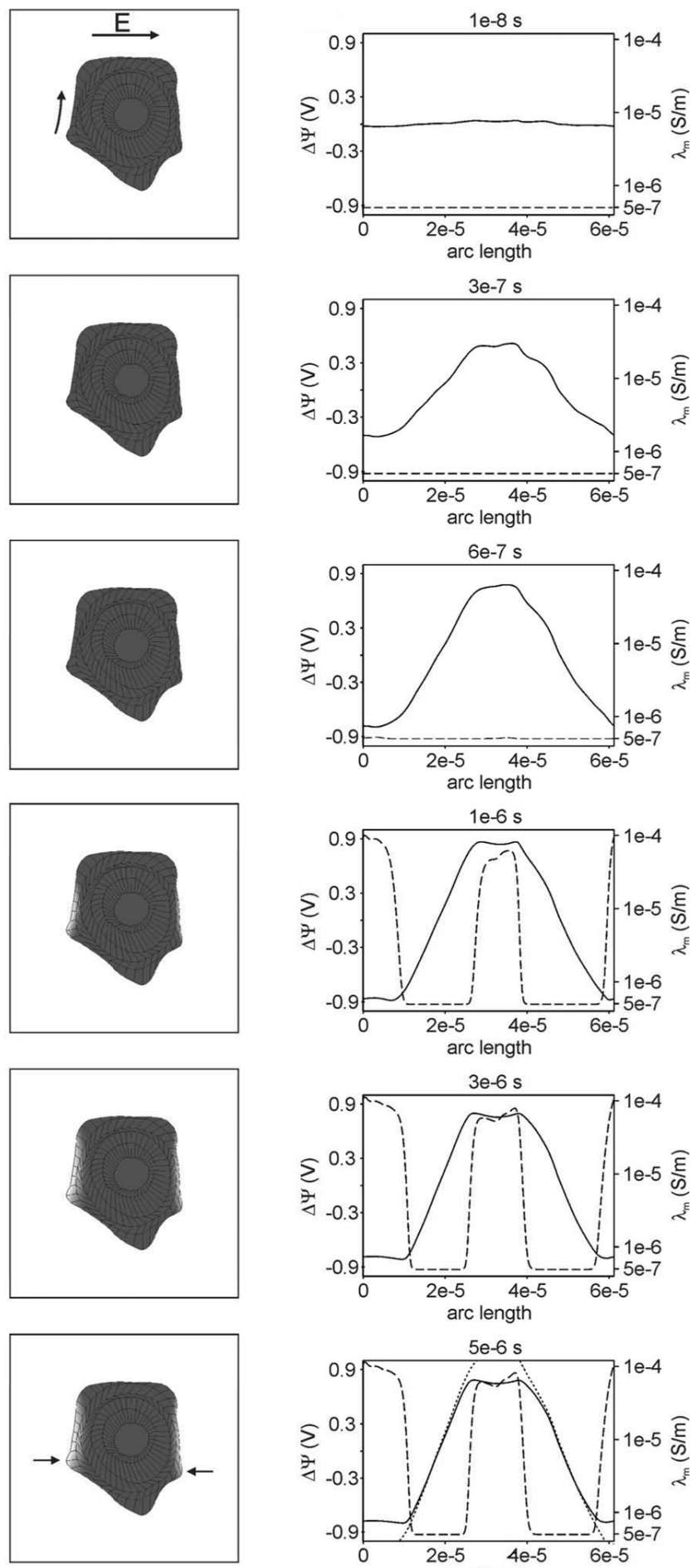

(c)

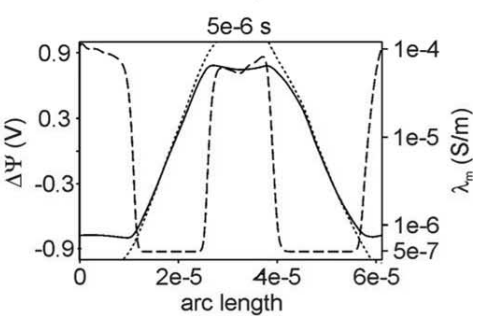

(d)

Fig. 6. Simulation of electroporation. (a) 3-D presentation of the changes in membrane conductivity $\lambda_{m}$ on a model of a spherical cell. The arrow marks the path along which $\Delta \Psi$ and $\lambda_{m}$ were sampled. (b) Corresponding $\Delta \Psi$ (solid curves) and $\lambda_{m}$ (dashed curves) as a function of arc length. (c) Changes in membrane

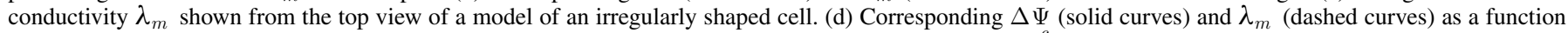
of arc length. Model settings are the same as in Fig. 5 . The dotted curves in panels b and d at time $5 \times 10^{-6} \mathrm{~s}$ show $\Delta \Psi$ for the nonporated cell. 


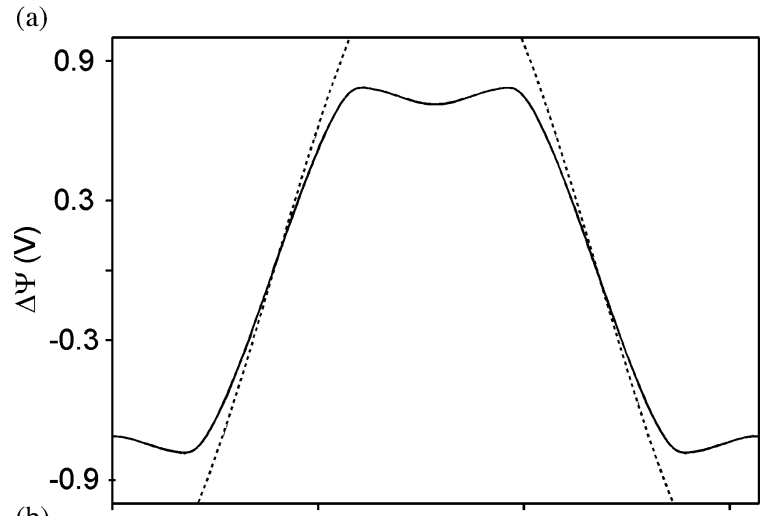

(b)

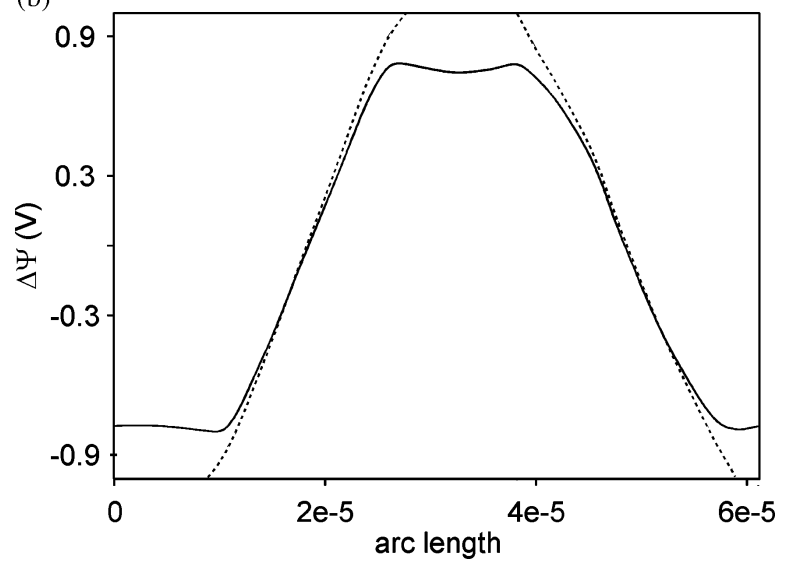

Fig. 7. Comparison of the spatial distribution of $\Delta \Psi$ on porated (solid curve) and nonporated cell (dotted curve) at time $5 \times 10^{-6} \mathrm{~s}$ for (a) a spherical cell, and (b) an irregularly shaped cell.
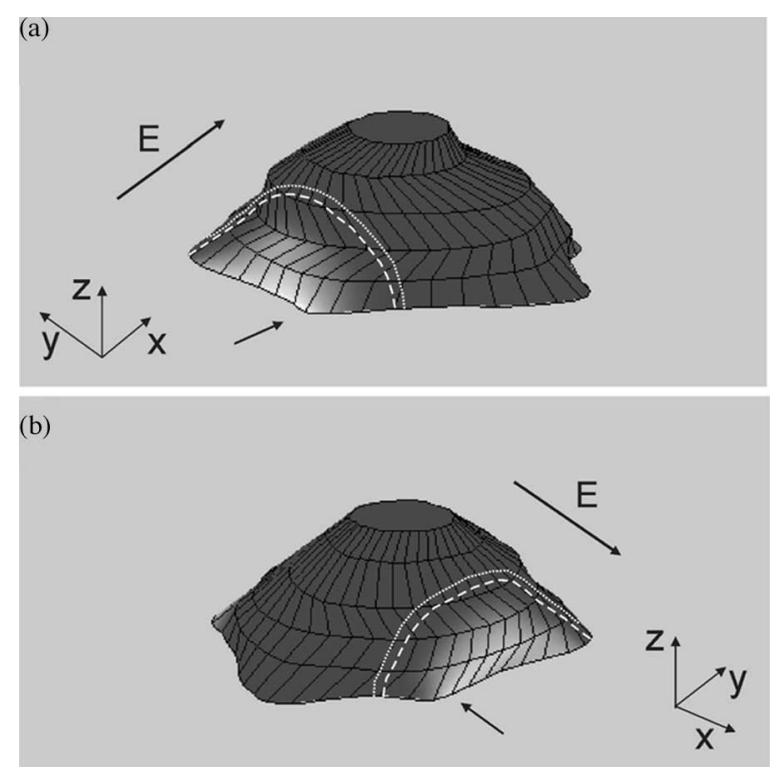

Fig. 8. Magnified side views of an irregularly shaped cell showing electroporated regions at time $5 \times 10^{-6} \mathrm{~s}$ in more detail. Dashed curve represents electroporated regions calculated with a time-dependent model, while dotted curve denotes the regions calculated with a steady-state model. The arrows show the sites of the cell, where electroporation was most pronounced. The field is parallel to the $x$-axis. with a steady-state model of $\Delta \Psi$, the value of $\Delta \Psi_{C}$ is generally overestimated. This is another argument in favor of the development of realistic time-dependent models of biological cells exposed to electric fields.

The model of electroporation used in our study is the asymptotic version of the electroporation model based on the Smoluchowski equation [49], [63], [64]. The assumption of this version that all pores have equal and time-independent radii ( $\sim 0.8 \mathrm{~nm}$, corresponding to the local minimum of the pore energy as a function of pore radius) is certainly only an approximation, and several approaches for modeling pores with variable and time-dependent radii have been proposed by different authors [33], [51], [65]-[67]. However, these approaches are partly incompatible between each other, and certain predictions of these models fail to agree with experimental evidence, e.g., the prediction that the largest pores develop at the very border of the porated area [67]. Moreover, the models based on the complete Smoluchowski equation [33], [66] consist of a considerably larger and more complex set of equations than the set of equations (6)-(10) used here. For these reasons, we chose the simple, asymptotic model of electroporation [30], [57], while many of the enhancements proposed by other authors could be incorporated into our modeling and calculation method without considerable technical difficulty.

\section{Experimental Monitoring of Electroporation}

The main advantage of the presented method of modeling is that it allows to evaluate the experimental results by comparing them to the quantities that can be calculated, but would be very difficult to measure directly. For example, electroporation is measured relatively easily by monitoring the transport of molecules (e.g., propidium iodide) through the cell membrane, but $\Delta \Psi$, particularly on short timescales, is more easily and reliably calculated than measured. Using the modeling approach described here, the same irregularly shaped cell from which the model in Figs. 1, 5(a), 6(c), and 8 was constructed was also used in the electroporation experiment. The cell was exposed to a single high-voltage electroporation pulse $(1000 \mathrm{~V} / \mathrm{cm}$, the same as in calculations) and the transport of molecules through electroporated cell membrane was monitored. Fig. 9 is a time sequence of fluorescence images showing the transport of fluorescent molecules through electroporated membrane [bright regions in Fig. 9(a)], into the cytosol [Fig. 9(b)], and with time into the nucleus [Fig. 9(c)], which becomes the most fluorescent due to the large number of binding sites for the dye. Comparison of the results in Figs. 6(c), 8, and 9(a) shows that the transport regions correspond to the calculated regions of increased membrane conductivity. We should note, however, that the temporal resolution in calculations was much higher than in the experiments. Namely, changes of membrane conductivity occur within a microsecond after the onset of the electric pulse, while the transport, limited by the sensitivity of the imaging camera, was only detected milliseconds after the pulse. In a separate study, using a fast and much more sensitive imaging system [68], we were able to detect molecular transport through the electroporated membranes already $60 \mu$ s after the start of the 


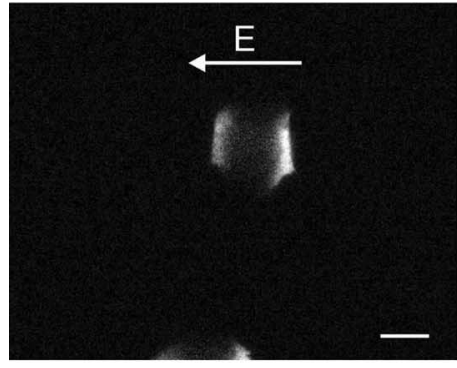

(a)

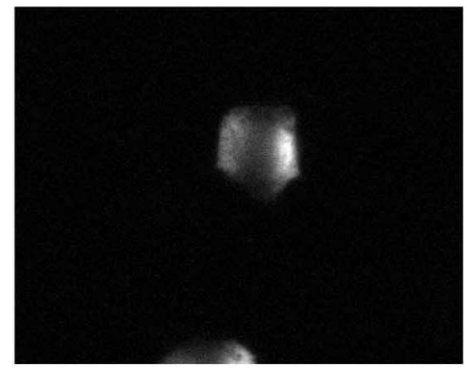

(b)

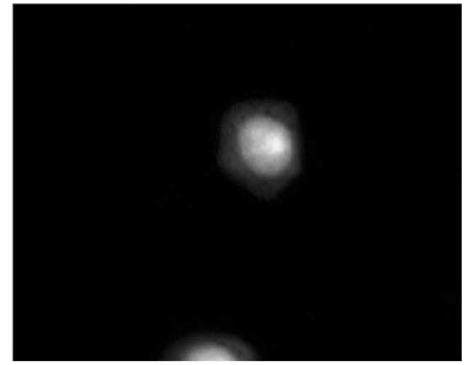

(c)

Fig. 9. Monitoring cell electroporation: (a) $100 \mathrm{~ms}$; (b) $1500 \mathrm{~ms}$; and (c) 3 min after pulse delivery. The cell was exposed to a single $200 \mu$ s, $400 \mathrm{~V}$ (1000 V/cm) rectangular pulse. To visualize the electroporated regions a fluorescent molecule propidium iodide was added to suspension before the pulse was applied. The bar in panel a corresponds to $10 \mu \mathrm{m}$.

pulse. However, whether an increase in membrane conductivity and the transport of molecules occur simultaneously remains to be elucidated.

\section{CONCLUSION}

A finite-element model of a time-dependent transmembrane voltage inducement and electroporation of a spherical and an irregularly shaped cell was presented. The model predicted a time-dependent increase in membrane conductivity in the regions with $\Delta \Psi>\Delta \Psi_{C}$ and a subsequent distortion of the spatial distribution of $\Delta \Psi$ in these regions, which is in agreement with reports in the literature. Our data show that in applications requiring a detailed knowledge of $\Delta \Psi$, such as cell membrane electroporation and studies of voltage-gated membrane channels, time-dependent modeling with realistic cell shapes should be used instead of the more elementary steady-state models and/or simplified shapes. The advantage of our method of model construction is the possibility to directly compare the experiments with calculations. As an example, we showed that regions of increased membrane conductivity, calculated on a model of an irregularly shaped cell, correspond to the regions of molecular transport observed experimentally on the same cell. Both models presented here-the time-dependent model of $\Delta \Psi$ and the model of electroporation - can be exploited further to study the behavior of more complicated cell assemblies, such as several irregularly shaped cells in contact or/and cell-to-cell interactions (gap junctions, etc.), in response to electric field exposure. The model of electroporation presented here can also be developed further by accounting for the pore size variation and time dependence.

\section{REFERENCES}

[1] P. Burnett, J. K. Robertson, J. M. Palmer, R. R. Ryan, A. E. Dubin, and R. A. Zivin, "Fluorescence imaging of electrically stimulated cells," $J$. Biomol. Screen., vol. 8, pp. 660-667, 2003.

[2] C. J. Huang, A. Harootunian, M. P. Maher, C. Quan, C. D. Raj, K. McCormack, R. Numann, P. A. Negulescu, and J. E. Gonzalez, "Characterization of voltage-gated sodium-channel blockers by electrical stimulation and fluorescence detection of membrane potential," Nat. Biotechnol., vol. 24, pp. 439-446, 2006.

[3] L. Tung and J. R. Borderies, "Analysis of electric field stimulation of single cardiac muscle cells," Biophys. J., vol. 63, pp. 371-386, 1992.

[4] V. Sharma and L. Tung, "Ionic currents involved in shock-induced nonlinear changes in transmembrane potential responses of single cardiac cells," Pflugers Arch., vol. 449, pp. 248-256, 2004.

[5] T. Y. Tsong, "Electroporation of cell membranes," Biophys. J., vol. 60, pp. 297-306, 1991
[6] E. Neumann, S. Kakorin, and K. Toensing, "Fundamentals of electroporative delivery of drugs and genes," Bioelectrochem. Bioenergy, vol. 48, pp. 3-16, 1999.

[7] J. Teissié, N. Eynard, B. Gabriel, and M. P. Rols, "Electropermeabilization of cell membranes," Adv. Drug. Del. Rev., vol. 35, pp. 3-19, 1999.

[8] H. Pauly and H. P. Schwan, "Uber die impedanz einer suspension von kugelformigen teilchen mit einer schale," Z. Naturforsch. B, vol. 14 pp. 125-131, 1959.

[9] T. Kotnik, F. Bobanović, and D. Miklavčič, "Sensitivity of transmembrane voltage induced by applied electric fields-A theoretical analysis," Bioelectrochem. Bioenergy, vol. 43, pp. 285-291, 1997.

[10] M. Hibino, M. Shigemori, H. Itoh, K. Nagayama, and K. Kinosita Jr.,, "Membrane conductance of an electroporated cell analyzed by submicrosecond imaging of transmembrane potential," Biophys. J., vol. 59, pp. 209-220, 1991.

[11] M. Hibino, H. Itoh, and K. Kinosita Jr, "Time courses of cell electroporation as revealed by submicrosecond imaging of transmembrane potential," Biophys. J., vol. 64, pp. 1789-1800, 1993.

[12] L. M. Mir, L. F. Glass, G. Serša, J. Teissié, C. Domenge, D. Miklavčič, M. J. Jaroszeski, S. Orlowski, D. S. Reintgen, Z. Rudolf, M. Belehradek, R. Gilbert, M. P. Rols, J. Belehradek, J. M. Bachaud, R. DeConti, B. Štabuc, M. Čemažar, P. Coninx, and R. Heller, "Effective treatment of cutaneous and subcutaneous malignant tumours by electrochemotherapy," Br. J. Cancer, vol. 77, pp. 2336-2342, 1998.

[13] R. Heller, R. Gilbert, and M. J. Jaroszeski, "Clinical applications of electrochemotherapy," Adv. Drug. Del. Rev., vol. 35, pp. 119-129, 1999.

[14] G. Serša, "The state-of-the-art of electrochemotherapy before the ESOPE study: Advantages and clinical uses," EJC. Suppl., vol. 4, pp. 52-59, 2006.

[15] G. Serša, D. Miklavčič, M. Čemažar, Z. Rudolf, G. Pucihar, and M. Snoj, "Electrochemotherapy in treatment of tumours," Eur. J. Surg. Oncol., vol. 34, pp. 232-240, 2008.

[16] E. Neumann, M. S. Ridder, Y. Wang, and P. H. Hofschneider, "Gene transfer into mouse lyoma cells by electroporation in high electric fields," EMBO J., vol. 1, pp. 841-845, 1982.

[17] M. J. Jaroszeski, R. Gilbert, C. Nicolau, and R. Heller, "In vivo gene delivery by electroporation," Adv. Drug. Del. Rev., vol. 35, pp. 131-137, 1999.

[18] M. Golzio, L. Mazzolini, A. Ledoux, A. Paganin, M. Izard, L. Hellaudais, A. Bieth, M. J. Pillaire, C. Cazaux, J. S. Hoffmann, B. Couderc, and J. Teissié, "In vivo gene silencing in solid tumors by targeted electrically mediated siRNA delivery," Gene Ther, vol. 14, pp. 752-759, 2007.

[19] A. R. Denet, R. Vanbever, and V. Preat, "Skin electroporation for transdermal and topical delivery," Adv. Drug. Del. Rev., vol. 56, pp. 659-674, 2004.

[20] N. Pavšelj and V. Preat, "DNA electrotransfer into the skin using a combination of one high- and one low-voltage pulse," J. Control Release, vol. 106, pp. 407-415, 2005.

[21] J. Lavee, G. Onik, P. Mikus, and B. Rubinski, "A novel nonthermal energy source for surgical epicardial atrial ablation: Irreversible electroporation," Heart Surg. Forum, vol. 10, pp. 92-101, 2007.

[22] E. Maor, A. Ivorra, J. Leor, and B. Rubinsky, "Irreversible electroporation attenuates neointimal formation after angioplasty," IEEE Trans. Biomed. Eng., vol. 55, no. 9, pp. 2268-2274, Sep. 2008.

[23] N. J. Rowan, S. J. MacGregor, J. G. Anderson, R. A. Fouracre, and O. Farish, "Pulsed electric field inactivation of diarrhoeagenic 
Bacillus cereus through irreversible electroporation," Lett. Appl. Microbiol., vol. 31, pp. 110-114, 2000.

[24] D. Gross, L. M. Loew, and W. Webb, "Optical imaging of cell membrane potential changes induced by applied electric fields," Biophys. J., vol. 50, pp. 339-348, 1986.

[25] L. M. Loew, "Voltage sensitive dyes: Measurement of membrane potentials induced by DC and AC electric fields," Bioelectromagn. Suppl., vol. 1, pp. 179-189, 1992.

[26] P. Marszalek, D. S. Liu, and T. Y. Tsong, "Schwan equation and transmembrane potential induced by alternating electric-field," Biophys. J., vol. 58, pp. 1053-1058, 1990.

[27] T. Kotnik, D. Miklavčič, and T. Slivnik, "Time course of transmembrane voltage induced by time-varying electric fields-A method for theoretical analysis and its application," Bioelectrochem. Bioenergy, vol. 45, pp. $3-$ 16, 1998.

[28] C. E. Miller and C. S. Henriquez, "Three-dimensional finite element solution for biopotentials: Erythrocyte in an applied field," IEEE Trans. Biomed. Eng., vol. 35, no. 9, pp. 712-718, Sep. 1988.

[29] E. C. Fear and M. A. Stuchly, "Modeling assemblies of biological cells exposed to electric fields," IEEE Trans. Biomed. Eng., vol. 45, no. 10, pp. 1259-1271, Oct. 1998.

[30] K. A. DeBruin and W. Krassowska, "Modeling electroporation in a single cell. I. Effects of field strength and rest potential," Biophys. J., vol. 77, pp. 1213-1224, 1999.

[31] M. Pavlin, N. Pavšelj, and D. Miklavčič, "Dependence of induced transmembrane potential on cell density, arrangement, and cell position inside a cell system," IEEE Trans. Biomed. Eng., vol. 49, no. 6, pp. 605-612, Jun. 2002.

[32] T. R. Gowrishankar and J. C. Weaver, "An approach to electrical modeling of single and multiple cells," in Proc. Nat. Acad. Sci. USA, 2003, vol. 100, pp. 3203-3208.

[33] R. P. Joshi, Q. Hu, and K. H. Schoenbach, "Modeling studies of cell response to ultrashort, high-intensity electric fields-Implications for intracellular manipulation," IEEE Trans. Plasma Sci., vol. 32, no. 4, pp. 16771686, Aug. 2004.

[34] G. Pucihar, T. Kotnik, B. Valič, and D. Miklavčič, "Numerical modeling of induced transmembrane voltage induced on irregularly shaped cells," Ann. Biomed. Eng., vol. 34, pp. 642-652, 2006.

[35] E. Neumann, "Electric field-induced structural rearrangements in biomembranes," Stud. Biophys., vol. 130, pp. 139-143, 1989.

[36] T. Kotnik and D. Miklavčič, "Theoretical evaluation of voltage inducement on internal membranes of biological cells exposed to electric fields," Biophys. J., vol. 90, pp. 480-491, 2006.

[37] J. Bernhard and H. Pauly, "Generation of potential differences across membranes of ellipsoidal cells in an alternating electrical field," Biophysik, vol. 10, pp. 89-98, 1973.

[38] T. Kotnik and D. Miklavčič, "Analytical description of transmembrane voltage induced by electric fields on spheroidal cells," Biophys. J., vol. 79, pp. 670-679, 2000.

[39] J. Gimsa and D. Wachner, "Analytical description of the transmembrane voltage induced on arbitrarily oriented ellipsoidal and cylindrical cells," Biophys. J., vol. 81, pp. 1888-1896, 2001.

[40] D. A. Stewart, T. R. Gowrishankar, and J. C. Weaver, "Transport lattice approach to describing cell electroporation: Use of a local asymptotic model," IEEE Trans. Plasma Sci., vol. 32, no. 4, pp. 1696-1708, Aug. 2004.

[41] T. R. Gowrishankar, A. T. Esser, Z. Vasilkoski, K. C. Smith, and J. C. Weaver, "Microdosimetry for conventional and supra-electroporation in cells with organelles," Biochem. Biophys. Res. Commun., vol. 341, pp. 1266-1276, 2006.

[42] K. C. Smith, T. R. Gowrishankar, A. T. Esser, D. A. Stewart, and J. C. Weaver, "The spatially distributed dynamic transmembrane voltage of cells and organelles due to 10-ns pulses: Meshed transport networks," IEEE Trans. Plasma Sci., vol. 34, no. 4, pp. 1394-1404, Aug. 2006.

[43] C. H. See, R. A. Abd-Alhameed, and P. S. Excell, "Computation of electromagnetic fields in assemblages of biological cells using a modified finitedifference time-domain scheme," IEEE Trans. Microw. Theory Tech. vol. 55, no. 9, pp. 1986-1994, Sep. 2007.

[44] W. Ying and C. S. Henriquez, "Hybrid finite element method for describing the electrical response of biological cells to applied fields," IEEE Trans. Biomed. Eng., vol. 54, no. 4, pp. 611-620, Apr. 2007.

[45] R. P. Joshi and K. Schoenbach, "Electroporation dynamics in biological cells subjected to ultrafast electrical pulses: A numerical simulation study," Phys. Rev. E, vol. 62, pp. 1025-1033, 2000.
[46] A. T. Esser, K. C. Smith, T. R. Gowrishankar, and J. C. Weaver, "Towards solid tumor treatment by irreversible electroporation: Intrinsic redistribution of fields and currents in tissue," Technol. Cancer Res. Treat., vol. 6 , pp. 261-273, 2007.

[47] R. P. Joshi, A. Mishra, and K. H. Schoenbach, "Model assessment of cell membrane breakdown in clusters and tissues under high-intensity electric pulsing," IEEE Trans. Plasma Sci., vol. 36, no. 4, pp. 1680-1688, Aug. 2008

[48] M. P. Rols, C. Delteil, M. Golzio, and J. Teissié, "Control by ATP and ADP of voltage-induced mammalian-cell-membrane permeabilization, gene transfer and resulting expression," Eur. J. Biochem., vol. 254 , pp. 382-388, 1998.

[49] J. C. Weaver and R. A. Mintzer, "Decreased bilayer stability due to transmembrane potentials," Phys. Lett., vol. 86, pp. 57-59, 1981.

[50] R. W. Glaser, S. L. Leikin, L. V. Chernomordik, V. F. Pastushenko, and A. I. Sokirko, "Reversible electrical breakdown of lipid bilayersFormation and evolution of pores," Biochim. Biophys. Acta, vol. 940, pp. $275-287,1988$.

[51] J. C. Weaver and Y. A. Chizmadzhev, "Theory of electroporation: A review," Bioelectrochem. Bioenergy, vol. 41, pp. 135-160, 1996.

[52] K. Kinosita and T. Y. Tsong, "Voltage-induced conductance in human erythrocyte membranes," Biochim. Biophys. Acta, vol. 554, pp. 479-497, 1979.

[53] L. M. Mir, H. Banoun, and C. Paoletti, "Introduction of definite amounts of nonpermeant molecules into living cells after electropermeabilizationDirect access to the cytosol," Exp. Cell. Res., vol. 175, pp. 15-25, 1988.

[54] S. Sixou and J. Teissié, "Exogenous uptake and release of molecules by electroloaded cells-A digitized videomicroscopy study," Bioelectrochem. Bioenergy, vol. 31, pp. 237-257, 1993.

[55] M. Schmeer, T. Seipp, U. Pliquett, S. Kakorin, and E. Neumann, "Mechanism for the conductivity changes caused by membrane electroporation of CHO cell-pellets," Phys. Chem. Chem. Phys., vol. 6, pp. 5564-5574, 2004

[56] M. Pavlin, M. Kandušer, M. Reberšek, G. Pucihar, F. X. Hart, R. Magjarević, and D. Miklavčič, "Effect of cell electroporation on the conductivity of a cell suspension," Biophys. J., vol. 88, pp. 4378-4390, 2005.

[57] J. C. Neu and W. Krassowska, "Asymptotic model of electroporation," Phys. Rev. E, vol. 59, pp. 3471-3482, 1999.

[58] L. Towhidi, T. Kotnik, G. Pucihar, S. M. P. Firoozabadi, H. Mozdarani, and D. Miklavčič, "Variability of the minimal transmembrane voltage resulting in detectable membrane electroporation," Electromagn. Biol. Med., vol. 27, pp. 372-385, 2008.

[59] N. Gamper, J. D. Stockand, and M. S. Shapiro, "The use of Chinese hamster ovary $(\mathrm{CHO})$ cells in the study of ion channels," J. Pharmacol. Toxicol. Methods, vol. 51, pp. 177-185, 2005.

[60] J. Teissié and M. P. Rols, "An experimental evaluation of the critical potential difference inducing cell membrane electropermeabilization," Biophys. J., vol. 65, pp. 409-413, 1993.

[61] D. Miklavčič, D. Šemrov, H. Mekid, and L. M. Mir, "A validated model of in vivo electric field distribution in tissues for electrochemotherapy and for DNA electrotransfer for gene therapy," Biochim. Biophys. Acta, vol. 1523 , pp. 73-83, 2000.

[62] M. N. Teruel and T. Meyer, "Electroporation-induced formation of individual calcium entry sites in the cell body and processes of adherent cells," Biophys. J., vol. 73, pp. 1785-1796, 1997.

[63] V. F. Pastushenko, Y. A. Chizmadzhev, and V. B. Arakelyan, "Electric breakdown of bilayer lipid membranes. II. Calculation of the membrane lifetime in the steady-state diffusion approximations," Bioelectrochem. Bioenergy, vol. 6, pp. 53-62, 1979.

[64] S. A. Freeman, M. A. Wang, and J. C. Weaver, "Theory of electroporation of planar bilayer membranes: Predictions of the aqueous area, change in capacitance, and pore-pore separation," Biophys. J., vol. 67, pp. 42-56, 1994.

[65] E. Neumann, K. Toensing, S. Kakorin, P. Budde, and J. Frey, "Mechanism of electroporative dye uptake by mouse B cells," Biophys. J., vol. 74, pp. 98-108, 1998.

[66] R. P. Joshi, Q. Hu, K. H. Schoenbach, and H. P. Hjalmarson, "Improved energy model for membrane electroporation in biological cells subjected to electrical pulses," Phys. Rev. E, vol. 65, pp. 041920-1-041920-8, 2002.

[67] W. Krassowska and P. D. Filev, "Modeling electroporation in a single cell," Biophys. J., vol. 92, pp. 404-417, 2007.

[68] G. Pucihar, T. Kotnik, D. Miklavčič, and J. Teissié, "Kinetics of transmembrane transport of small molecules into electropermeabilized cells," Biophys. J., vol. 95, pp. 2837-2848, 2008. 


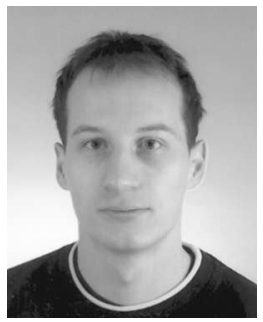

Gorazd Pucihar was born in 1976. He received the Ph.D. degree in electrical engineering from the University of Ljubljana, Ljubljana, Slovenia.

$\mathrm{He}$ is a Research Associate at the Faculty of Electrical Engineering, University of Ljubljana. His current research interests include experimental investigation and numerical modeling of electroporation and related phenomena.

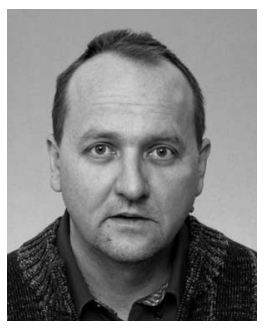

Damijan Miklavčič was born in 1963. He received the Ph.D. degree in electrical engineering from the University of Ljubljana, Ljubljana, Slovenia.

$\mathrm{He}$ is a Professor at the Faculty of Electrical Engineering, University of Ljubljana, where he is also the Head of the Laboratory of Biocybernetics. He is engaged in the field of biomedical engineering. His current research interests include electroporationassisted drug and gene delivery, including cancer treatment by means of electrochemotherapy, tissue oxygenation, modeling of biological processes, and

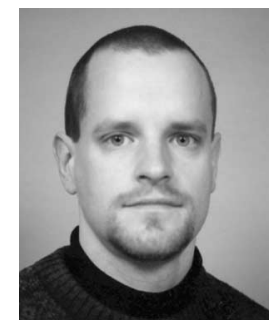

Tadej Kotnik was born in 1972. He received the $\mathrm{Ph} . \mathrm{D}$. degree in electrical engineering from the University of Ljubljana, Ljubljana, Slovenia and the $\mathrm{Ph}$.D. degree in biophysics from University Paris XI, Orsay, France.

$\mathrm{He}$ is an Assistant Professor at the Faculty of Electrical Engineering, University of Ljubljana. His current research interests include membrane electrodynamics and related biophysical phenomena (particularly membrane electroporation), as well as computational research in number theory. 